\title{
A new monitoring process of future topics for innovation and technological analysis: informing Germanys' innovation policy
}

\author{
Nora Weinberger • Michael Decker • Torsten Fleischer • \\ Jens Schippl
}

Received: 2 July 2013 / Accepted: 12 September 2013 /Published online: 1 October 2013

(C) The Author(s) 2013. This article is published with open access at Springerlink.com

\begin{abstract}
Technology assessment (TA) is defined as problemoriented transdisciplinary research that aims at working out solutions for societal problems. It provides advice to those in politics, science and wider society on issues related to research, technology and innovation. There is widespread agreement that TA should start at an early phase in order to contribute to responsible strategic technology development. If we assume limited resources, the question remained, however, how priority setting of TA should be organised. The German Federal Ministry for Education and Research launched a research project to answer this question based on their funding strategy. In this paper, we propose an approach to determine when TA should be conducted in a given situation, and which methodological approach of TA is most promising: using a 'coarse radar', several topics were identified in a two-pronged search approach. Then relevant topics were selected with the help of experts and the decision-making body itself. Finally, using a 'fine radar', detailed problem analyses of the prioritised topics were made to present concrete suggestions for funding by the BMBF (pre-projects). The paper evaluates briefly the methodology and discusses initial findings of the method evaluation process.
\end{abstract}

\footnotetext{
N. Weinberger $(\bowtie) \cdot$ M. Decker $\cdot$ T. Fleischer $\cdot$ J. Schippl Institute for Technology Assessment and Systems Analysis, Karlsruhe Institute of Technology (KIT),

Hermann-von-Helmholtz-Platz 1, 76344 Eggenstein-Leopoldshafen, Germany

e-mail: nora.weinberger@kit.edu

M. Decker

e-mail: michael.decker@kit.edu

T. Fleischer

e-mail: torsten.fleischer@kit.edu

J. Schippl

e-mail: jens.schippl@kit.edu
}

Keywords Future topics · Innovation and technology analysis · Problem-orientation · Expert participation · Strategic funding $\cdot$ Agenda-setting

\section{Introduction}

Technology Assessment (TA) is a well-established practice which aims at offering research-based advice concerning research, technology and innovation to policy-makers, the science community and society. In doing so, TA helps deal with societal challenges caused by technology. Part of the TA program is the early identification, observation and analysis of scientific and technological trends or emerging technologies and corresponding societal developments. This so-called technology push closely interacts with public research and development funding where specific forms of technological innovation are seen as essential to solve 'societal challenges' [1]. Moreover, TA can provide political recommendations for action or guidelines for the prevention or reduction of identified risks as well as enable an improved take-up of opportunities. A key consideration, here, is the ambivalent role of technology. Technical applications fulfill their functions, but also have an effect on the natural and social environment [2].

In addition to the technology push perspective, TA has to confront the so called "grand challenges" by providing knowledge that helps to prevent or solve societal problems. As new technological developments are part of the solution this is described as 'demand pull'; the related TA is commonly termed problem-oriented research [3, 4]. As these societal problems cannot usually be assigned to a single scientific discipline, an "interdisciplinary development of solutions to such problems is inevitable [5]". This corresponds with theoretical positions on problem-oriented research in general which is often described as "mode2 knowledge production" 
[6], "technoscience" or "post-normal science" [7]. These concepts propose that transdisciplinary research is needed in order to deal with extra-scientific problems. The potential to serve as a solution for such problems becomes the most prominent quality criterion, yet this cannot be provided sufficiently by scientific measures alone. Additional involvement of 'extended peer communities' is required in order to gain 'robust knowledge' for societal decision-making. Therefore, science has to merge into another mode ('mode2') or become 'post normal'. This means that science needs socio-political and academicanalytical knowledge resources and 'feedback-loops' from independent experts and stakeholders. The multi-criteria description of the problem at stake becomes the most relevant methodological starting point since a comprehensive description of the problem is necessary to identify feasible solutions.

There is a widespread agreement that TA should start at an early stage in order to contribute to a reasonable and responsible strategic technology development. However, looking at potential TA topics resulting out of the technology push and the demand pull approach, described above, we can expect an oversupply. This aims to resolve the 'conundrum' of which societal challenges and technological developments TA should focus on, as this research question has not yet attracted proper scientific attention. Thus, against the background of several societal challenges waiting to be solved, and financial and human resources limitations meaning not all topics can be tackled simultaneously, the authors suggest a generic approach that closes this loophole in current knowledge. We posit that the proposed approach allows a continual monitoring of new TA topics and makes it possible to decide which topics should be given priority and when the appropriate time for them is.

The remainder of this paper is organised as follows: the second section describes the conceptual framework conditions; in the third section we depict a generic approach, in an effort to provide an appropriate systematic and cyclical monitoring process for new TA topics; in the fourth section the methodological implementation within the project 'ITA Monitoring: Identifying New Topics for Innovation and Technology Analysis' funded by the German Federal Ministry for Education and Research (BMBF) is shown; in the fifth section we analyse briefly the actual experience of implementing the methodology and finally, the sixth section comprises conclusions.

\section{Conceptual framework conditions}

Referring to the suggested methodology for the identification of 'new' TA topics to be assessed in the near future and as the proposed methodological approach was tested in a monitoring process for a decision-making body, the German Federal Ministry of Education and Research (BMBF), the following framework requirements have to be met.
First, the term 'new' stands not only for questions not yet examined but also for up to now insufficiently investigated once. Second, the Ministry asked for research questions focused on a 'mid-term' time frame of five to ten year $\mathrm{s}$, rather than long-term Foresight-processes with a time frame of about 15 years. On the BMBF homepage one can find the following description of the Foresight-process:

"The Foresight is an instrument to systematically look into the longer-term future and has the task to identify relevant developments at an early stage, to interpret them and to let them be known in the current research and innovation policy. Foresight provides contextual knowledge that prepares the politics, economy, science and society on key technologies and technology needs. Thereby, Foresight is not a trend analysis on which predictions can derive. Rather, the process picks up the complex innovation process and makes the uncertainty of future developments manageable. But, also the international competitive environment is taken into consideration" [8] (translation by the authors).

Parallel to the Foresight-process, the mid-term ITA approach adopted by the BMBF aims to make knowledge available to the actors in the innovation process, in order to improve their decision-making regarding research, technology and innovation. The BMBF's brochure contains the statement:

"The innovation and technology analysis (ITA) of the BMBF seeks to identify fields of socially accepted technological progress, illustrate potential, identify political scope and develop options for research and innovation. ITA is intended to provide guidance in a highly technologised society and contribute to promoting more humane, socially just and environmentally sound technological processes. Drawing on the proven methods and studies of technology assessment (TA), ITA is a strategic concept for the analysis and evaluation of technologies which combines research and practice in its comprehensive approach" [9] (translation by the authors).

Thus innovation and technology analysis, ITA, is the framework used by the German Research Ministry. One of the main reasons for this was the perception that TA was thought to be negatively connoted with "technology arrestment" or "technology aversion" [10] (at least in some circles). Although the ITA rhetoric has not gained prominence outside Germany, we will use it in the following sections, in which the methodology and its implementation are described. This is partly due to the fact that the underlying program is to a large extent similar to the TA program, as TA opens itself to the innovation process, e.g. through the concept known as 'responsible innovation'. In addition, we present the joint process with the BMBF. 


\section{The general methodological approach}

This chapter focuses on the description of a process of priority-setting which was largely based on the specific approach of expert assessment. The methodology was developed as a tool for decision-making on future ITA topics in the context of science and technology policy-making. Based on this, we recommend the following process:

To fulfill the demand of a 'mid-term' radar [11] as determined by the Ministry, a systematic investigation needs to explicitly take the time frame of potentially relevant developments into account. Generally, an early and opportune exploration of relevant topics for ITA is advised in order to enable the decision-making body to pursue strategic funding in such a manner that ITA, as a key principle, is combined with innovation policy requirements and new forms of 'governance' at an early stage $[12,13]$. This intention places high demands on the scope of the initial monitoring process, the definition of relevant fields for such in-depth investigations, the appraisal of the future relevance of potential topics and necessary future knowledge. In order to deal with a broad range of potential topics and to provide for a transparent methodological approach, the process of searching and setting priorities was structured as follows (see Fig. 1). Phase A, Phase B and Phase C.

Phase A) The 'coarse radar' covers the screening of potential topics. Its main task, besides the creation of adequate overview knowledge, is the identification of the consolidated thematic fields for Phase B.

Phase B) The selection process involves external experts/ stakeholders and is conducted in close co-operation with the decision-making body. Therefore, in
Phase B topics for further processing within ITA monitoring (or processing outside of ITA, e.g. within specialised research programmes or Foresight) are selected. The topic selection of the second project cycle differs methodologically from the other two cycles. While the choice of topics is made by external experts in the first and third cycle, the choice of topics is conducted by the projectteam and representatives of the decision-making body in the second cycle. Hence, a kind of 'tandem process' for the selection of relevant and urgent topics concerning ITA is established.

Phase C) The selected topics are explored in greater detail ('fine radar') for possible integration in the subsequent ITA process and for revision as suitable 'instruments' (such as ITA short studies, ITA studies, thematic field or project calls, topic transfer in funding programmes).

Whereas Phases $\mathrm{A}, \mathrm{B}$ and $\mathrm{C}$ are performed three times in a cycle (A-B-C, A-B-C, A-B-C), the screening process in Phase $\mathrm{A}$ is also conducted parallel to $\mathrm{B}$ and $\mathrm{C}$ throughout the process. Although the objective of the Ministry was to initiate a continuous process, the Ministry decided to perform only three cycles in order to prove the functionality of the methodological approach in the first instance.

\section{Implementation experience}

Based on the previous considerations, the methodological approach was tested in a monitoring process for a decisionmaking body, the German Federal Ministry of Education and Research (BMBF). The research project "ITA-Monitoring:
Fig. 1 General monitoring approach

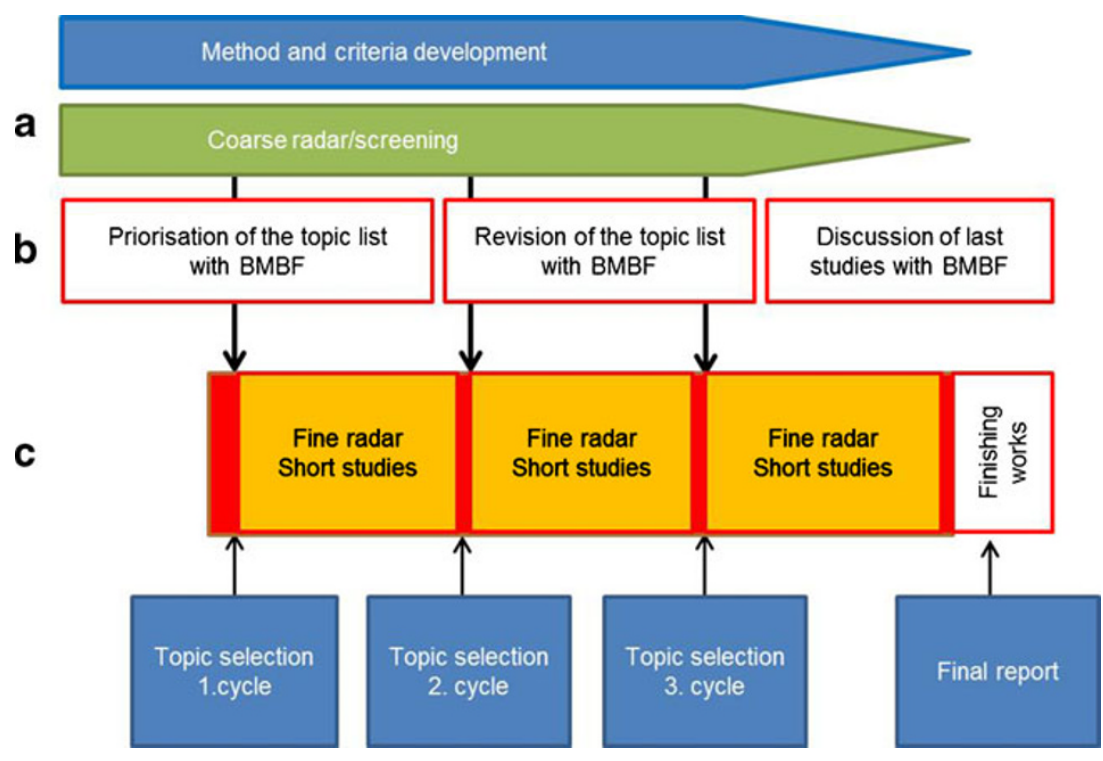


Identification of new topics for innovation and technology analysis" aimed at identifying topics to be assessed in the near future by ITA and compiling relevant research questions. Furthermore, the project aimed at providing the decisionmaking body direction on future agenda settings for their policy development. Consequently, the generic approach, described in the section above, was implemented as follows during the project (see Fig. 2):

\section{Coarse radar or screening}

The thematic range of the coarse radar was based on the traditional distinction between a technology push and demand pull perspective in innovation research, ${ }^{1}$ which was applied to the identification of new topics for ITA. On the one hand, the intended and unintended side-effects of technology within the social context should be examined in the interest of a commitment to a 'policy' of continuous development and improvement (technology-induced TA). On the other, social demands or challenges, and the extent to which their impact may be resolved or at least be mitigated by the use of technologies should be identified (problem-based TA). Thus, even if this distinction merely generates an artificial division, ${ }^{2}$ it offers a good opportunity to initiate systematic research and provides appropriate search strategies.

For a successful monitoring process the selection of information sources was of decisive importance to ensure a comprehensively wide search area. As part of the technologyoriented approach the search process for potentially relevant ITA topics started with the technology development itself. The following were analysed, amongst other sources: i) scientific and technical journals, ii) general trend analyses of relevant future research institutions and business consultancies, iii) the results of representative population surveys on the expectations and attitudes towards science and technology, iv) reports and contributions to (technical) conferences, v) trade and conventions or vi) reports by committees of experts and funding programs. In addition, the search process included vii) Foresight-studies and roadmaps (given that the introductory chapters of these commonly refer to social and political trends) $[17,18]$, viii) market research studies, ix) trade and technical journals as well as newspapers and $\mathrm{x}$ ) social science journals and reports by foundations. Assessment of the aforementioned types of information sources was complemented by bibliometric and patent analyses. Thus, the basis of the screening was a comprehensive search of documented statements about new technology developments and developers' statements as to their promised relevance. This relevance was verified by ongoing developments, demands and challenges

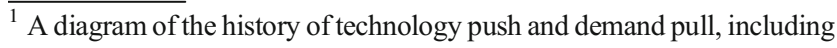
critical statements, can be found in [15].

${ }^{2}$ Cf. for example [16].
}
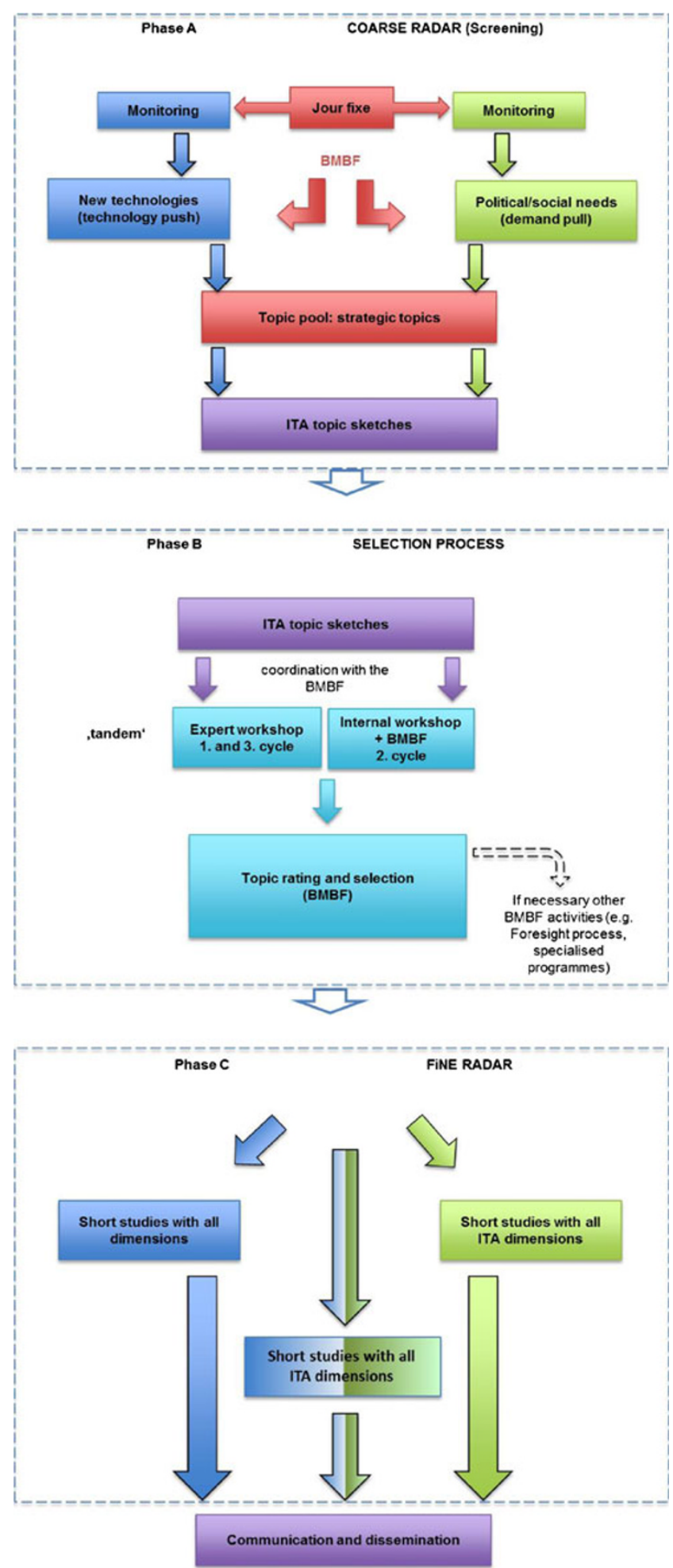

Fig. 2 The monitoring process (cf. [14], adapted by the authors)

related to social trends and political movements. Based on comprehensive literature research of concrete statements regarding political and/or social trends, developments, and needs, the science and technology-related social and political needs were explored. The methodology is based on the 
assumption that social needs and problematic situationsassumed by different authors - have already been thought of and published.

After the review of publication references thematic clustering was conducted. In the project the key clusters were: 1 ) energy, 2) education, 3) demography and society, 4) health, 5) globalisation, 6) information and communication technologies (ICT) and the internet, 7) consumption and products, 8) materials and technology, 9) mobility, 10) economy and finances, 11) the environment, 12) living and urban development and 13) the world of work. Through our search strategy 433 topics were identified in the first project cycle, 225 (new) topics were found in the second cycle, and 89 (new) topics in the third cycle. The significantly higher number of topics identified in the first cycle was due to the fact that in the subsequent cycles only 'new trend' references were taken into account.

In the second methodological step of the coarse radar the above mentioned distinction between the technology push and the demand pull perspective was eliminated as each newlyfound topic was investigated under the ongoing monitoring process to discover whether it would satisfy both aspects of these complementary perspectives. Thus, technical developments had to be discussed in relation to social, political and economic consequences expressed by relevant stakeholders $[19,20]$. Furthermore, an indication of the development of particular technological solutions to meet social needs was necessary. A relation between a technological solution and a social conflict or need has to be identified; otherwise a topic was not labelled a 'strategic ITA topic' and was not further developed in this phase.

As a result of this coarse radar, so-called 'topic sketches' were created, in which technical procedures were presented with the first indications of their social implications. These were not summarized evaluations of the topic, but rather validated assumptions as evidenced by sources, that this might well be a topic relevant for ITA. Thus, the sketches covered three aspects: 'What is the issue?', 'Why is it important?', and 'What needs clarification?'. Due to the wide range of the search process a large number of such topic sketches were created. The first cycle led to 53 topic sketches, the second resulted in 34 and the third cycle resulted in 35 topic sketches.

\section{Selection process}

In the subsequent selection process decisions were taken on which topic sketch should be developed into a so called 'short study' during Phase $\mathrm{C}$ for further use by the BMBF. This selection was deliberatively supported through a kind of 'feedback loop' by independent external experts. As a first step, a discursive workshop was carried out attaching special importance to the nomination and prioritisation of research topics as well as expert statements concerning the content of the topic sketch. This included, for example, pro- and conarguments for their assessment, reference to thematically similar areas and existing studies. To create a productive atmosphere for discussion, both, 'generalists' for ITA questions and 'advocates' representing the technical-scientific, the economic, ecological, social, political and health disciplines were invited. Thus, although the intention was to allow all points of view to be represented, the experts reproduced their positions based on their experience. In order to have group sizes as uniform as possible, eight to ten generalists and specialists were recruited. Through this workshop setting, with its 'clash' of generalists and specialists, evidence-based decisionmaking according to benchmarks such as 'importance' and 'relevance', but also by 'urgency' (see further below in the text) was made possible. Moreover, this assessment and ranking took into account both science and policy as the topics were also 'filtered' by the decision-making body in the last methodological step of this phase.

As a starting point, all experts received the selected topic sketches in alphabetic order and were requested to nominate the most relevant topics (in their opinion) on a scale from 0 (irrelevant) to 3 (relevant), whereby each expert could allocate points up to a maximum of number of topics*1,5). This advance ranking represented the first expert feedback on the coarse radar results. As no topic was allocated zero points in the evaluation, and even the topic with the lowest score was considered essential by at least one expert, the strategic topic selection resulting from Phase A was confirmed by the experts. The point allocation which showed disagreements in the expert panel with a bipolar distribution of many 3's and 0's was also interesting. These results were then anonymized and aggregated in a ranking list of recommended research priorities. This advance ranking of the topics represented the methodological starting point of the workshops, which were designed in such a way that all topic 'candidates' discussed were discursively dismissed or selected until the envisaged number of topics remained.

The aim of the workshop by contrast to the evaluation of the topics in the plenary, was for the experts to judge the importance and relevance of the topics based on their respective set of experiences. As a result, a mutual exchange of experts' personal arguments for the ranking took place during the workshop sessions. It was important to give the experts the option to accept other experts' arguments and to adjust their own evaluation of the topic accordingly. In addition, the workshop was designed for congruence and consensus. To enable this, the workshop was planned in such a way that it was possible for a topic categorised as 'hardly relevant' during the advance ranking to be promoted into the top ten. In our view the arguments that lead to a topic being 'moved up' are of great interest. Furthermore, the discussion was stimulated by the mechanism that if one topic was promoted, another had to be demoted. In this way, it was possible to achieve the indented focused debate, as wells as draw together the experts' arguments for and against 
a single topic going forward in the research process. Thus, the workshop was able to identify topics which were considered by the experts to be relevant and important for ITA. Much of the final hour of the workshop was devoted to a discussion evaluating the final top 20 topics regarding their urgency. The experts categorised the topics into four groups of urgency: 'very, very urgent', 'very urgent', 'urgent' and 'further observation' (see Table 1 for more information).

Finally, the selection process was completed during a workshop including the project team and the decisionmaking body, who evaluated the topics assessed during the expert workshops for their 'strategic fit' with the policy body. Because of the overlap in scientific and political relevance, topics which were judged neither 'very, very urgent' nor 'very urgent' or even 'urgent' by the experts still have been selected by the BMBF. Table 1 shows the final selection and prioritization of topics for further research by the BMBF, and those be developed in Phase C.

Fine radar or the 'thematic in-depth look'

Only the topics identified through the previous selection procedure were developed into so-called short studies (through a process termed the 'fine radar' to distinguish it from the 'coarse radar') which were based on the criteria described above. The aim of a short study is to provide a comprehensive description of the problem at stake. This appraisal with regard to its potential relevance for ITA encompasses the following dimensions:

1. Technical-scientific dimension: ITA is always based on a technology to be assessed. Thus, analyses depend on this technical-scientific development, its benefits and problemsolving potential, just like the state of art, scientific evidence and the intended and non-intended consequences.

2. Economic dimension: An analysis of the current or future economic relevance of the identified technology at national and international level is decisive (e.g. market potential, cost-saving potential, labour market effects). Hence, the value-added and utilisation chain should be evaluated. This includes, amongst others, the identification of potential utilisation restraints (procedure, product, patents etc.), market drivers for the identified technology, competitors and market regulation.

3. Ecological dimension: Another aspect is the evaluation of the ecological dimension, which focuses on relevant environmental approaches, e.g. the environmental compatibility of products and processes and the recyclability of products. The analysis should also focus on the potential of an identified technology to solve conflicts, e.g. by evaluating the pros and cons of a technology as identified by environmental organisations.

4. Social and community dimension: Of crucial importance for ITA is the social perspective of a certain technological development or a technical field. This raises the questions of whether and how the identified technology contributes to an improved quality of life and prosperity, and which demands regarding quality of life and prosperity are expressed and gain public attention. Public acceptance or rejections plays a major role in the market penetration of a technology. Thus, the question of whether the need for the technology and its social consequences should be announced, and who should do it, requires further investigation. In addition, the potential emergence of conflict and consensus as well as socially relevant uncertainties and risks should be examined. A further analysis should scrutinise whether culturally-shaped and traditional behavioural patterns (education, media usage, mobility behaviour) are affected by technological developments.

5. Political dimension: The assessment of a technological solution must take into account the political situation in which the technological development is taking place. The relevance of the political situation is dependent upon the stage of the policy-making process and the nature of the ongoing political discourse. If a technology or need is already recognised at the political level, the question arises which political actors are participating in the political debate. This essentially involves the meeting of actors and their contrary or consensus discussions. In this
Table 1 Areas for further research chosen by the BMBF

\begin{tabular}{|c|c|c|}
\hline First project cycle & Second project cycle & Third project cycle \\
\hline Crowdsourcing & Automobile data security & 'Fresh on the garbage' \\
\hline Electromobility & ICT in the financial sector & Big data for social research \\
\hline $\begin{array}{l}\text { Food: technological trends } \\
\text { and innovations }\end{array}$ & $\begin{array}{l}\text { Social conditions of efforts } \\
\text { in technical enhancement } \\
\text { of human skills }\end{array}$ & $\begin{array}{l}\text { Newly organised innovation Actors: } \\
\text { possibilities and limits exemplified } \\
\text { by 'nanotechnology' }\end{array}$ \\
\hline Smart Grids & & Service robots in care arrangements \\
\hline 'Sticky information' & & Location-based services \\
\hline \multicolumn{3}{|l|}{$\begin{array}{l}\text { Unconventional natural gas } \\
\text { and mineral oil }\end{array}$} \\
\hline Non-medical neuroscience‘application & & \\
\hline
\end{tabular}


context, the regulation, legislative and funding needs also have to be analysed. Moreover, the extent to which the topic has to predominantly national character should be examined, or whether international relations also play a role. Further, the potential influence at each political level (state, federation, European Union etc.) has to be studied.

6. Health dimension: The identified technology's potential to solve health problems should also be considered. This includes analysis of potential sanitary consequences and sources of danger; as well as of possible positive and negative statements by health and patient organisations concerning the technology.

All available information as well as evaluations by experts of supporting and precaution-oriented issues (e.g. in-depth studies or thematic field calls) should be concisely prepared and embedded in the German context (ITA preliminary study). Moreover, the short study shows potential opportunities and risks and provides an early diagnosis of potential restraints and supporting factors for innovations. Based on this problem analysis, concrete proposals for the methodological identification of an ITA need were developed. Thus, the short study does not represent an ITA study, but an extensive situation analysis (the state of science and technology) with specific proposals for the methodical update or specification of ITA objectives (cf. [21]). The methodological recommendations of the short studies set the ground for an in-depth ITA analysis. These studies were then developed during the third phase of the project for all fifteen topics specified by the BMBF (cf. Table 1).

\section{The generic approach pursued within the ITA-monitoring project: a first review}

A first review of this approach shows that the stringent problem-orientation is very practicable and effective in fulfilling the demand of a 'mid-term radar', which allows the identification and prioritisation of TA topics. Moreover, the method contributes to agenda-setting and policy development. In particular, around 750 potential topics for further TA research resulted from the coarse radar. These overlapping topics could be clustered around various societal problems (e.g. food security, sustainable consumption, globalisation, social conditions for human enhancement, children's obesity) and technology innovations (e.g. ICT developments such as avatars, methane hydrate, crowd sourcing, service robots). So, in the first instance the approach generally enables the identification of future topics for TA. Secondly, it was shown that a selection and prioritisation of topics is feasible with the help of external experts (see Table 1). Further, the exchange of arguments during this workshop was of value in itself. It gave an important indication of challenges and sub-topics that should be covered in the short studies. As a result of the experts' arguments and advice (for example, of incorrect focus or combining topic sketches), some topic sketches were modified and included in the subsequent project cycle. Using this multi-cyclical process, as we propose, these kinds of topics are not lost, thus providing the need for a continuous process.

Nonetheless, the proposed methodology pursued within this project implies an effect from the twofold selection process, which lies in the differing decision rationales of project participants from the world of science and active policy-making. Thus, the decision for prioritising one project above another was a combination of both actors' rationales, whereas the final decision lay with the organising Ministry. On the one hand, this might appear to be problematic for observers with a strongly sciento-centric perspective. On the other, it supports stronger acceptance within policy-making bodies and fosters a more substantial impact. In most cases there was agreement between the scientific and the political actors on decisions of relevance. But there were exceptions. For example, internal and external experts assessed the topics concerning water (infrastructure) as highly relevant and urgent. Nevertheless, none of the waterrelated topics reached Phase $\mathrm{C}$ because they did not fit the political agenda of the BMBF. By contrast, the topic 'vertical farming', which the experts did not assess as relevant or urgent, was implemented in two BMBF funding projects. One could note it would be valuable to examine this further in order to better understand what the internal rationale is that plays a role in these decisions, and what this could mean for further topic selection processes (in the context of policy-making). However, in our experience, this examination is virtually impossible, as the decision-making body did not allow any insight into the final internal decision-making processes, the pressures and constraints and the competing rationales and departments within the Ministry. A possible solution to this dilemma could be a workshop by the project-team and representatives of the decision-making body. This was established in the tandem process in the second project cycle (see Fig. 1): Here, notes from representatives of the decision-making body indicated what was decided upon later. For example, topic 'xy' was ranked as 'very urgent' by the experts, but a representative of the decision-making body refused this topic as "at the moment little attention is being paid to the topic according to the current in-house opinion about that problem; the topic is 'old hat'. If the final decision is made on the basis of political relevance, these effects will tend to occur.

In addition, some of the topics undergo a 'career progression' during the expert workshops. As mentioned above (see chapter 4.2), all experts received the selected topic sketches with a request to nominate the most relevant topics (according to their opinion). As no topic was allocated zero points and even the topics with the lowest scores were considered essential by at least one expert, the strategic topic selection made by the project in Phase A was confirmed by the experts. All selected topics were judged to be relevant and important by 
the academic experts in the "ivory tower"-during the personal pre-ranking prior to the workshop. However, after listening to the arguments of other experts during the discursive negotiation process, their evaluation of the topics changed. As a result, topics 'climbed' and others were some 'relegated', as shown in the following two examples. During the first project cycle the topic 'sticky information' was positioned 41st in the pre-ranking survey, whereas it advanced to the top six after the panel discussion during the workshop ('voting up'). By contrast, the topic 'artificial photosynthesis' was argued down from second place to 19th during the third project cycle ('voting down'). Both examples can be seen as good evidence for the effectiveness of the workshop design.

Sometimes the political decision-making process (which topic should be further developed in Phase $\mathrm{C}$ ) took so long that the topic had become a media story (for example 'food waste' and 'big data/sticky information'). This was due to the broad and comprehensive search process, resulting in topics cross-cutting all the Ministry's thematic areas and thus, too allembracing for one representative of the Ministry. Hence, an internal feedback loop in the Ministry was necessary in order to avoid thematic overlap with the currently funded research areas and to achieve as high political relevance as possible.

Thus far, there has been no systematic assessment of the impact of the Phase C pre-projects as "it is extremely complicated to define and measure impacts in a systematic and reliable manner" [22]. Moreover, questions arise: 'When does an outcome actually have impact?', 'What are appropriate quality markers?', 'What changes in policy would constitute impact?' and 'What time frame for impact is realistic?'. This shows the difficulty in measuring impact as well as its indefinable nature. Nevertheless, it can be stated that all of the proposed pre-projects have been officially accepted by the BMBF and are currently being considered in order to prepare the BMBF's next ITAmonitoring phase. Moreover, the BKA's (Germany's Federal Criminal Police Office) Department of Technology Monitoring and the BSI's (Germany's Federal Office for Information Security) Department C1 'Security in Nets' showed interest in the early identification of trends concerning internet technology presented in the 'sticky information' study (see Table 1). As a result, the authors of the 'sticky information' study had a dialogue with the department head in order to enable a similar monitoring process for them regarding the net (and ICT technologies). In addition, political impact may be achieved at the regional and national level e.g. the Department of Waste Management (Karlsruhe), the Ministry of Rural Affairs, Food and Consumer Protection (Baden-Württemberg), the German Federal Ministry of Food, Agriculture and Consumer Protection and the German Federal Environmental Agency showed great interest in the study 'food waste'. A research agenda in the field of e-mobility was published that addresses several topics that were highlighted in the corresponding short study of the monitoring-project.

\section{Conclusions}

Technology Assessment is a form of problem-oriented transdisciplinary research that aims at offering research-based advice concerning research, technology and innovation to policy-makers, the science community and society. Issues of investigation for TA are found in different ways - firstly, one may distinguish between reactive and proactive approaches. In the former, TA reacts to questions posed by policymakers, civic groups or society as a whole. In the latter, TA performs a role described by Smits and Leyten (1991) as the "tracker dog" of TA [23]: as an ongoing process of identifying and analysing developments in science, technology, and innovation, anticipating their (potential) consequences, and informing or even organising discussions around them. Particularly in the latter context the question remains how relevant information can be gathered and how the priority-setting of future research topics in respect of 'new' TA topics should be organised. Thus, the identification and prioritisation of future societal problems is a central element of the methodological approach presented in this paper. The implementation experience showed that this proposed methodology is effective, with regard to the research question. It allows a continual monitoring of new TA topics and makes it possible to decide which topics should be given priority and when the appropriate time for each one is. It represents an advance in this field and addresses the gaps in common knowledge. The project provided usable results by providing direction for priority-setting in the form of short studies.

In addition, the authors suggest an in-depth evaluation of the interaction processes and dynamics between the experts. Furthermore, it would seem to be appropriate to provide knowledge about the effects and process to improve understanding (i.e. the authority structures in such group opinion processes). This is of particular importance in processes which are aimed at achieving a final consensus. Besides this, it would be sensible to monitor further changes in policy regarding the proposed pre-projects.

In summary, the approach presented here is a good method for identifying relevant future TA topics, whereas the progress in implementing the topics on the agenda, as selected by the experts, is frequently lacking due to administrative and rationality constraints.

Acknowledgments The authors acknowledge funding from the German Federal Ministry of Education and Research and the cooperation with Futures Technologies Consulting, part of the VDI Technology Center $\mathrm{GmbH}$, who coordinated activities from the technology push perspective. We would also like to thank the experts for their valuable contribution. These include the 'discursive sparring partners' of the two selection workshops, who engaged themselves in a methodologically complex selection approach. We also thank our colleagues at the Institute for Technology Assessment and Systems Analysis at the Karlsruhe Institute of Technology. They were of an inestimable value in finding topics, assessing relevance, and preparing and reviewing the short studies. 
Open Access This article is distributed under the terms of the Creative Commons Attribution License which permits any use, distribution, and reproduction in any medium, provided the original author(s) and the source are credited.

\section{References}

1. Diedrich A, Upham P, Levidow L, van den Hove S (2011) Framing environmental sustainability challenges for research and innovation in European policy agendas. Environ Sci Policy 14(8):935-939

2. Grunwald A (2002) Technikfolgenabschätzung —Eine Einführung. Edition Sigma, Berlin

3. Bechmann G, Frederichs G (1996) Problemorientierte Forschung. Zwischen Politik und Wissenschaft. In: Bechmann G (ed) Praxisfelder der Technikfolgenforschung Konzepte, Methoden, Optionen. Campus, Frankfurt/M, pp 11-37. (Veröffentlichungen des Instituts für Technikfolgenabschätzung und Systemanalyse (ITAS), Bd. 3)

4. Gethmann CF (1999) Rationale Technikfolgenbeurteilung. In: Grunwald A (ed) Rationale Technikfolgenbeurteilung. Konzepte und methodische Grundlagen. Springer, Berlin, pp 1-10

5. Decker M, Fleischer T (2010) When should there be which kind of technology assessment? A plea for a strictly problem-oriented approach from the very outset. Poiesis Prax. doi:10.1007/s10202-0100074-6

6. Gibbons M, Limoges C, Nowotny H, Schwartzman S, Scott P, Trow $M$ (1994) The new production of knowledge: dynamics of science and research in contemporary societies. Sage, London

7. Funtowicz S, Ravetz JR (2001) Post-Normal Science. Science and Governance and Conditions of Complexity. In: Decker M (ed) Interdisciplinarity in Technology Assessment: Implementation and its Chances and Limits. Springer, Heidelberg/Berlin, pp 15-24

8. BMBF (German Federal Ministry for Education and Research) (2013) The Foresight process. BMBF Web. http://www.bmbf.de/de/ 12673.php. Accessed 26 August 2013

9. Bundesministerium für Bildung und Forschung BMBF (ed) (2001) Innovations- und Technikanalyse. Zukunftschancen erkennen und realisieren. BMBF, Bonn

10. Baron W, Zweck A (2001) Bedarf und Nutzen von ITA für die Wirtschaft. TA-Datenbank-Nachrichten 10(2):9-16

11. Bode OF (2007) Wissenschaftsbasierte Beratung für politische Entscheidungsfindung und/oder für die Exekutive. In: Bora A,
Bröchler S, Decker M (eds) Technology Assessment in der Weltgesellschaft. Edition Sigma, Berlin, pp 51-60

12. Meyer-Krahmer F (1999) Technikfolgenabschätzung im Kontext von Innovationsforschung und Globalisierung. In: Petermann T, Coenen R. (eds) Technikfolgenabschätzung in Deutschland. Bilanz und Perspektiven. Campus-Verlag, Frankfurt/M, pp 197-216

13. Malanowski N, Zweck A (2008) Identifikation neuer Themen im Bereich Politikberatung. In: Bröchler S, Schützeichel R (eds) Politikberatung. Lucius \& Lucius, Stuttgart

14. Decker M, Fleischer T, Schippl J, Weinberger N (2012) Zukünftige Themen der Innovations- und Technikanalyse: Methodik und ausgewählte Ergebnisse. KIT Scientific Publishing 2012 (KIT Scientific Reports 7605), Karlsruhe

15. Nemet GF (2009) Demand-pull, technology push, and government-led incentives for non-incremental technical change. Res Policy 38:700-709

16. Nelson R, Winter S (1977) In search of useful theory in innovation. Res Policy 6:36-76

17. Kostoff R, Schaller RR (2001) Science and technology roadmaps. IEEE Trans Eng Manag 48(2):132-143

18. Fleischer T, Hocke P, Kastenholz H, Krug HF, Quendt C, Spangenberg A (2010) Evidenzbewertung von gesundheitsrelevanten Auswirkungen synthetischer Nanopartikel. Ein neues Verfahren für die Unterstützung von Governance-Prozessen in der Nanotechnologie? In: Aichholzer G, Bora A, Bröchler S, Decker M, Latzer M (eds) Technology Governance. Der Beitrag der Technikfolgenabschätzung. Edition Sigma, Berlin, pp 239-246

19. Bröchler S, Simonis G (1998) Konturen des Konzepts einer innovationsorientierten Technikfolgenabschätzung und Technikgestaltung. TA-Datenbank-Nachrichten 7(1):31-40

20. Gethmann CF, Sander T. (1999) Rechtfertigungsdiskurse. In: Grunwald A, Saupe S (eds) Ethik in der Technikgestaltung. Praktische Relevanz und Legitimation. Springer-Verlag, Heidelberg, Berlin, New York, pp 117-151

21. Decker M, Ladikas M (eds) (2004) Bridges between science, society and policy. Technology assessment - Methods and impacts. SpringerVerlag, Heidelberg, Berlin, New York (Wissenschaftsethik und Technikfolgenbeurteilung, Bd. 22)

22. Hennen L, Bellucci S, Berloinik R, Cope D, Cruz-Castro L et al. (2004) Towards framework for assessing the impact of technology assessment. In: Decker M, Ladikas M (eds) Bridges between Science, Society and Policy: Technology Assessment-Methods and Impacts. Berlin, pp 57-86

23. Smits R, Leyten J (1991) Technology Assessment: waakhond of speurhond? [Technology Assessment: watchdog or tracker dog?]. Kerckebosch, Zeist 